\title{
Efficacy of triple therapy with a proton pump inhibitor, levofloxacin, and amoxicillin as first-line treatment to eradicate Helicobacter pylori
}

\author{
M. Castro-Fernández, E. Lamas, A. Pérez-Pastor, M. Pabón, R. Aparcero, J. Vargas-Romero, \\ J. L. Larraona and M. Romero-Gómez \\ Unit for the Clinical Management of Digestive Diseases and CIBERehd. Hospital Universitario de Valme. Sevilla, Spain
}

\begin{abstract}
Background: triple therapy including a proton pump inhibitor, clarithromycin, and amoxicillin (PPI-CA) is the first-choice treatment used for $H$. pylori eradication. The efficacy of this treatment is declining of late, and alternative therapies are currently under evaluation.

Objectives: to evaluate the efficacy, safety and compliance of a triple therapy with a PPI, amoxicillin and levofloxacin (PPI-LA) - replacing clarithromycin - for the eradication of $H$. pylori.

Methods: the study included 135 patients (65\% women), mean age 53 years, with dyspeptic symptoms and $H$. pylori infection proven by a positive urease rapid test, histological analysis, or C13-urea breath test. Diagnosis: non-investigated dyspepsia 48.9\%, functional dyspepsia 36.3\%, and ulcerative dyspepsia $14.8 \%$. Treatment was indicated with a proton pump inhibitor at usual doses, amoxicillin $1 \mathrm{~g}$, and levofloxacin $500 \mathrm{mg}$, administered jointly during breakfast and dinner for 10 days. We studied the performance of this triple therapy and its effects using a questionnaire, and effectiveness by the negativity of the C13-urea breath test after 6-8 weeks after treatment discontinuation. Per protocol, we compared the effectiveness of PPI-LA with a control group of 270 patients treated with PPI-CA for 10 days.

Results: 130 patients (96.2\%) could complete the treatment and follow-up protocol. Effectiveness (intention to treat) was $71.8 \%$ (97/135) and 74.6\% (per protocol) (97/130). Sixteen patients $(11.8 \%)$ had well-tolerated adverse effects, except for 5 subjects (3.7\%) who dropped out. PPI-CA was effective (per protocol) in 204 patients out of $270(75.5 \%)$ in the control group.

Conclusions: triple therapy with a PPI, amoxicillin and levofloxacin for 10 days is a well-tolerated treatment that is easy to comply with; however it has low efficiency - less than $80 \%$ - and is not recommended as a first-choice treatment for $H$. pylori eradication. Similar results were obtained with the classic triple therapy using a PPI, clarithromycin and amoxicillin.
\end{abstract}

Received: 19-01-09.

Accepted: 06-03-09.

Correspondence: Manuel Castro Fernández. Unit for the Clinical Management of Digestive Diseases. Hospital Universitario de Valme. Carretera de Cádiz, s/n. 41014 Sevilla, Spain. e-mail: mcastrof@meditex.es manuel.castro.sspa@juntadeandalucia.es
Key words: Triple therapy. Levofloxacin. Helicobacter pylori.

Castro-Fernández $M$, Lamas E, Pérez-Pastor A, Pabón M, Aparcero R, Vargas-Romero J, Larraona JL, Romero-Gómez M. Efficacy of triple therapy with a proton pump inhibitor, levofloxacin, and amoxicillin as first-line treatment to eradicate Helicobacter pylori. Rev Esp Enferm Dig 2009; 101: 395-402.

\section{INTRODUCTION}

Triple therapy combining a proton pump inhibitor (PPI) with two antibiotics, preferably clarithromycin and amoxicillin (PPI-CA), is the first-choice treatment in the eradication of Helicobacter pylori (H. pylori) (1-3). The efficacy of this treatment has declined in recent years, being now usually below $80 \%$ and, in some studies, lower than $70 \%$ (4-9), probably due to increased resistance to clarithromycin. Recent publications show a higher efficacy $(>80 \%)$ of a new triple therapy combining a PPI, amoxicillin and levofloxacin (PPI-LA) replacing clarithromycin as first-line treatment to eradicate $H$. pylori, this being considered an alternative treatment because of the lack of effectiveness of triple therapy with PPI-CA (10-15). In this study we determined the effectiveness, compliance and safety of PPI-LA triple therapy for 10 days, given as firstline treatment to eradicate $H$. pylori in our health area.

\section{METHODS}

Study design: a prospective, observational, single-center study. Period of study: 2007-2008.

We included 135 consecutive patients with dyspeptic symptoms and $H$.pylori infection diagnosed by positivity 
for the C13-urea breath test, urease rapid test, or histological analysis. It was determined that a patient was infected when having a positive result for any of these tests. Eighty-eight patients (65\%) were female and $47(35 \%)$ were male, with an average age of 53 years (18-80); 33 were smokers $(24.5 \%)$. Patients under 18 years of age were not included, as well as patients with alleged difficulty in complying with therapy, serious illnesses, previous eradicating treatment, gastric surgery, intolerance, or allergy to any of the drugs included in the study. In 69 of 135 cases (51\%) an oral endoscopic analysis was performed, obtaining antral gastric mucosa biopsies for histological analysis and/or urease rapid test, and the following diagnoses were made: functional dyspepsia $=49$ cases $(36.3 \%)$, and peptic ulcer disease or ulcerative dyspepsia $=20$ cases $(14.8 \%)$. The remaining 66 cases (48.9\%) were diagnosed using the C13-urea breath test and managed with the "test and treat" strategy (non-investigated dyspepsia).

\section{Treatment}

Omeprazol $20 \mathrm{mg} / 12 \mathrm{~h}$ (or another PPI at equivalent dose), amoxicillin $1 \mathrm{~g} / 12 \mathrm{~h}$, and levofloxacin $500 \mathrm{mg} / 12 \mathrm{~h}$ for 10 days. All three drugs should be taken together, preferably during breakfast and dinner. Other PPIs used were lansoprazole $30 \mathrm{mg} / 12 \mathrm{~h}$, pantoprazole $40 \mathrm{mg} / 12 \mathrm{~h}$, rabeprazole $20 \mathrm{mg} / 12 \mathrm{~h}$, and esomeprazole $40 \mathrm{mg} / 12 \mathrm{~h}$. We confirmed the effectiveness of triple therapy using the negativity of the C13-urea breath test at 6-8 weeks after treatment completion. The emergence of significant adverse effects and adherence to treatment were monitored through interrogation.

The analysis of results was performed using the intention-to-treat (ITT) and per protocol (PP) strategies. In the ITT analysis all patients who started treatment were included. In the PP analysis patients who completed treatment protocols, at least $90 \%$ of doses, and follow-up, keeping on the scheduled date for clinical evaluation and the breath test analysis, were included. All patients accepted the treatment provided, including levofloxacin, and were informed about the importance of $H$. pylori infection, the need for proper treatment, and the possibility of side effects.

We compared the effectiveness of the study therapy under investigation, by PP, with a control group of 270 consecutive patients with dyspepsia and $H$. pylori infection treated with omeprazole $20 \mathrm{mg} / 12 \mathrm{~h}$ (or another PPI at equivalent doses), clarithromycin $500 \mathrm{mg} / 12 \mathrm{~h}$, and amoxicillin $1 \mathrm{~g} / 12 \mathrm{~h}$ (PPI-CA) for 10 days, from 2006 to 2007. The control group was composed of 102 male patients $(37.8 \%)$ and 168 females $(62.2 \%)$, with an average age of $47( \pm 30)$ and diagnosed as follows: non-investigated dyspepsia in 123 cases (45.6\%), functional dyspepsia in 95 cases $(35.2 \%)$, and ulcerative dyspepsia in 52 cases (19.2\%). The diagnosis of H. pylori infection and the ef- fectiveness of treatment were analyzed by the methods already described.

The present study complies with the regulations of the Ethics and Clinical Research Committees of our hospital.

\section{RESULTS}

\section{Completion of treatment and side effects}

One hundred and thirty patients out of 135 (96.2\%) successfully conducted treatment with PPI-LA and underwent the C13-urea breath test on the scheduled date. Five patients $(3.7 \%)$ conducted the treatment only for 3-4 days due to adverse effects. Side effects that led to treatment discontinuation were: nausea and vomiting (2 cases), nausea ( 2 cases), and seizures ( 1 case).

Sixteen patients $(11.8 \%)$ had some adverse effect. They are listed in table I.

Table I. Adverse effects of triple therapy with a PPI, levofloxacin, and amoxicillin for 10 days

\begin{tabular}{lc}
\hline Adverse effect & Number of cases (\%) \\
\hline Nausea & $8(5.9 \%)$ \\
Metallic taste & $4(2.9 \%)$ \\
Abdominal pain & $3(2.2 \%)$ \\
Diarrhea & $3(2.2 \%)$ \\
Vomiting & $2(1.4 \%)$ \\
Oral thrush & $2(1.4 \%)$ \\
Myalgia & $2(1.4 \%)$ \\
Seizures & $1(0.7 \%)$ \\
Any adverse effect & $16(11.8 \%)$ \\
\hline
\end{tabular}

\section{Effectiveness of treatment}

Study group: treatment proved to be effective in 97 patients $(71.8 \%)$ and failed in 33 patients $(24.4 \%)$. In 5 patients of $135(3.7 \%)$ treatment was unsuccessful.

The efficacy found was $71.8 \%(97 / 135)(95 \%$ confidence interval, 64.2-79.4\%) in the intention-to-treat analysis, and $74.6 \%$ (97/130) (95\% confidence interval, $67.1-82.1 \%)$ in the per protocol analysis. There was no significant difference between patients with functional, ulcerative, or non-investigated dyspepsia.

Control group: treatment using PPI-CA proved to be effective (PP) in 204 out of 270 patients $(75.5 \%)(95 \%$ confidence interval, 70.4-80.6\%), and failed in 66 out of 270 patients $(24.4 \%)$. There was no significant difference in effectiveness of treatment between PPI-LA and PPI-CA.

\section{DISCUSSION}

Triple therapy combining a PPI with two antibiotics, preferably amoxicillin and clarithromycin (PPI-CA), for 
at least 7 days is the first-choice regimen to eradicate $H$. pylori infection that is widely accepted in Europe and the United States. During the Second Spanish Consensus Conference (2005) it was recommended as standard firstchoice regimen the use of a PPI (usual dose) together with $1 \mathrm{~g}$ of amoxicillin and $500 \mathrm{mg}$ of clarithromycin every 12 hours, or RCB $400 \mathrm{mg}$ every $12 \mathrm{~h}$ (this drug not currently available) with the same antibiotics. In case of allergy to amoxicillin, metronidazole $500 \mathrm{mg}$ every $12 \mathrm{~h}$ (1.2) should be chosen. During the Third Conference of Consensus at Maastricht (2007) this triple therapy was recommended as first-line treatment. The same guideline is also present in other consensus documents produced in Italy by the "Cervia II Working Group" (2007) and in the United States by the American College of Gastroenterology $(2007)(3,16,17)$.

As a conclusion achieved during the First Conference of Consensus at Maastricht (1997), only treatments with an efficiency higher than $80 \%$ (intention to treat) should be recommended for clinical practice (18). Graham et al., in a recent review, assess and confirm that treatment to eradicate $H$. pylori infection should have an efficiency above 80 or $85 \%$, intention to treat or per protocol, respectively (5). Gisbert et al., (2000), published a meta-analysis on the effectiveness of triple therapy with a PPI, clarithromycin and amoxicillin or metronidazole/tinidazole, reviewing 22 previously reported studies (1996-1999). They found similar efficacy in the intention to treat and per protocol analyses (81 and 84\%) (19). In this meta-analysis, the observed efficiency of the eradicating treatment was very close to or exceeded $90 \%$ (20). These results are not obtained in studies recently published, which usually show the effectiveness of classic triple therapy to be below $80 \%$, even when treatment was extended for up to 10 days $(5-9,21)$. Boixeda et al., (2003) found the same trend in a study of 890 patients, and detected an eradication rate of $77 \%$ (22). Calvet et al., (2005) reported an eradication rate of triple therapy (intention to treat) of 73 and $79 \%$ for 7 and 10 days of treatment, respectively (21). In our health area, during years 2005-2007, the eradication rate with the triple therapy (per protocol) was $70 \%$ for
10 days. This low efficiency led us to consider other therapeutic strategies.

Levofloxacin is a fluoroquinolone with a broad spectrum of activity against gram (+) and gram (-) bacteria, including $H$. pylori. It is highly effective for respiratory, urinary tract, skin, and soft tissue infections. In recent years, several studies have been published evaluating the effectiveness of triple therapy containing levofloxacin in the eradication of $H$. pylori. A recent meta-analysis shows that therapy with PPI-LA, especially for 10 days, is more effective and better tolerated as second-line than quadruple therapy in eradicating $H$. pylori (23). Gisbert et al. published two studies where a high multisite effectiveness of triple therapy with PPILA for 10 days was found as second- and third-line treatment in the eradication of $H$. pylori $(24,25)$. The loss of effectiveness of triple therapy with PPI-CA motivates the use of triple therapy with levofloxacin replacing clarithromycin as first-line treatment for the eradication of $H$. pylori. In this regard, several studies showing an acceptable efficacy of this treatment, higher than $80 \%$ (Table II), considered it an alternative choice to standard triple therapy in areas where, due to increasing resistance to clarithromycin, a progressive loss of effectiveness was found (10-15). This situation, actually present in our health area, motivated this study. We have used high-dose levofloxacin, as previously pointed out by other authors $(11,12,14,15,24,25)$, in order to increase treatment effectiveness. We noted that, in our experience, the effectiveness of triple therapy with PPI-LA was $75 \%$ in the per-protocol analysis, which is lower than the results reported by other authors. Treatment is simple and well tolerated, but due is not recommended in view of its low efficacy, at least in our health area, as first-choice regimen for the eradication of $H$. pylori (despite a high failure rate obtained with triple therapy using PPI-CA). The progressive increase of resistance to fluoroquinolones identified by some authors may justify the low effectiveness of triple therapy with these antibiotics. Bogaerts et al. (in Belgium) detected during the years 2003-2004 that $16.8 \%$ of H. pylori strains were resistant to fluoroquinolones,

Table II. Efficacy of triple therapy with levofloxacin, as first-line therapy in the eradication of Helicobacter pylori

\begin{tabular}{lccccc}
\hline $\begin{array}{l}\text { References } \\
\text { (10-15) }\end{array}$ & $\begin{array}{c}\text { Number of } \\
\text { patients }\end{array}$ & Drugs/days & $\begin{array}{c}\text { Levofloxacin } \\
\text { doses }\end{array}$ & $\begin{array}{c}\text { Effectiveness } \\
\text { ITT (\%) }\end{array}$ & $\begin{array}{c}\text { Effectiveness } \\
\text { PP (\%) }\end{array}$ \\
\hline Cammarota et al. (2000) & 50 & R-L-T/7 & $500 \mathrm{mg} / 24 \mathrm{~h}$ & 92 & 92 \\
& 50 & R-L-A/7 & $500 \mathrm{mg} / 24 \mathrm{~h}$ & 90 & 90 \\
Antos et al. (2006) & 30 & E-L-A/7 & $500 \mathrm{mg} / 12 \mathrm{~h}$ & 86.7 & 92.9 \\
Marcio et al. (2006) & 80 & E-L-A/10 & $500 \mathrm{mg} / 12 \mathrm{~h}$ & 93.7 & 87 \\
Nista et al. (2006) & 100 & E-L-C/7 & $500 \mathrm{mg} / 24 \mathrm{~h}$ & 84.4 & 90.6 \\
Gisbert et al. (2007) & 64 & RBC-L-A/10 & $500 \mathrm{mg} / 12 \mathrm{~h}$ & 80.5 \\
Gisbert et al. (2008) & 75 & O-L-A/10 & $500 \mathrm{mg} / 12 \mathrm{~h}$ & 82.7 & 84.5 \\
\hline
\end{tabular}

ITT: intention to treat; PP: per protocol; RBC: ranitidine bismuth citrate; R: rabeprazole; L: levofloxacin; A: amoxicillin; T: tinidazole; E: esomeprazole; O: omeprazole; C: clarithromycin. 
while A. Zullo et al. (in Italy) detected in 2004-2006 a higher resistance rate $(19 \%)$, particularly to levofloxacin (26-28).

The low effectiveness of PPI-CA and PPI-LA demands other treatment strategies such as the currently-discussed association of a PPI with three antibiotics: amoxicillin, clarithromycin and metronidazole, simultaneously or sequentially. These treatments have been reported to yield very good results in the eradication of $H$. pylori $(29,30)$.

\section{REFERENCES}

1. Monés J, Gisbert JP, Borda F, Domínguez-Muñoz E, y Grupo Conferencia Española de Consenso sobre Helicobacter pylori. Indications, diagnostic test and Helicobacter pylori eradication therapy. Recommendations by the 2nd Spanish Consensus Conference. Rev Esp Enferm Dig 2005; 97: 348-74.

2. Gisbert JP, Calvet X, Gomollón F, Monés J, y Grupo Conferencia Española de Consenso sobre Helicobacter pylori. Tratamiento erradicador de Helicobacter pylori. Recomendaciones de la II Conferencia Española de Consenso. Med Clin (Barc.) 2005; 125: 301-16.

3. Malfertheiner P, Megraud F, O’Morain C, Bazzoli F, El-Omar E, Graham D, et al., for The European Helicobacter Study Group (EHSG). Current concepts in the management of Helicobacter pylori infection: the Maastricht III Consensus Report. Gut 2007; 56: 77281.

4. Vilaichone RK, Mahachai V, Graham DY. Helicobacter pylori diagnosis and management. Gastroenterol Clin North Am 2006; 35: 22947.

5. Graham DY, Lu H, Yamaoka. Therapy for Helicobacter pylori infection can be improved. Drugs 2008; 68: 725-36.

6. Cavallaro LG, Egan B, O’Morain C, Di Mario F. Treatment of Helicobacter pylori infection. Helicobacter 2006; 11 (Supl. 1): 36-9.

7. Rokkas T, Sechopoulos P, Robotis I, Margantinis G, Pistiolas D. Cumulative $\mathrm{H}$. pylori eradication rates in clinical practice by adopting first-and second-line regimens proposed by the Maastricht III Consensus and a third-line empirical regimen. Am J Gastroenterol 2008; 103: $1-5$.

8. Vakil N, Megraud F. Eradication therapy for Helicobacter pylori. Gastroenterology 2007; 133: 985-1001.

9. Egan BJ, Marzio L, O'Connor H, O’Morain C. Treatment of Helicobacter pylori infection. Helicobacter 2008; 13(Supl. 1): 35-40.

10. Cammarota G, Cianci R, Cannizzaro O, Cuoco L, Pirozzi G, Gasbarrini A, et al. Efficacy of two one-week rabeprazole/levofloxacin-based triple therapies for Helicobacter pylori infection. Aliment Pharmaco Ther 2000;14: 1339-43.

11. Antos D, Schneider-Brachert W, Bästlein E, Hänel C, Haferland C, Buchner M, et al. 7-day triple therapy of Helicobacter pylori infection with levofloxacin, amoxicillin, and high-dose esomeprazole in patients with know antimicrobial sensitivity. Helicobacter 2006; 11: $39-45$.

12. Marzio L, Coraggio D, Capodicasa S, Grossi L, Cappello G. Role of the preliminary susceptibility testing for initial and after failed therapy of Helicobacter pylori infection with levofloxacin, amoxicillin, and esomeprazole. Helicobacter 2006; 11: 237-242.

13. Nista E, Candelli M, Zocco MA, Cremonini F, Ojetti V, Finizio R, et al. Levofloxacin-based triple therapy in first-line treatment for Helicobacter pylori eradication. Am J Gastroenterol 2006; 101: 1985-90.

14. Gisbert JP, Fernández-Bermejo M, Molina-Infante J, Pérez-Gallardo B, Prieto-Bermejo AB, Mateos-Rodríguez JM, et al. First-line triple therapy with levofloxacin for Helicobacter pylori eradication. Ali- ment Pharmacol Ther 2007; 26: 495-500.

15. Gisbert JP, Fernández-Bermejo M, Molina-Infante M, Pérez-Gallardo B, Prieto-Bermejo AB, Mateos-Rodríguez JM, et al. Levofloxacin, amoxicillin, and omeprazole as first-line triple therapy for Helicobacter pylori eradication. Helicobacter 2008; 13: 460-1.

16. Caselli M, Zullo A, Maconi G, Parente F, Alvisi V, Casetti T, et al., for the Working Group of the Cervia II Meeting. "Cervia II Working Group Report 2006": Guidelines on diagnosis and treatment of Helicobacter pylori infection in Italy. Dig Liver Dis 2007; 39: 782-9.

17. Chey WD, Wong BCY, and the Practice Parameters Committee of the American College of Gastroenterology. American College of Gastroenterology Guideline on the Management of the Helicobacter pylori Infection. Am J Gastroenterol 2007; 102: 1808-25.

18. Malfertheiner P, Mégraud P, O`Morain C, Bell D, Bianchi Porro G, Deltenre M, et al. Current European concepts in the management of Helicobacter pylori infection: the Maastricht Consensus Report. The European Helicobacter pylori Study Group (EHPSG). Eur J Gastroenterol Hepatol 1997; 9: 1-2.

19. Gisbert JP, González L, Calvet X, García N, López, Roque M, et al Protom pump inhibitor, clarithromycin an either amoxycillin or nitrimidazole. A meta-analysis of eradication of Helicobacter pylori. Aliment Pharmacol Ther 2000;14: 1319-28.

20. Gisbert JP, Boixeda D, Aller R, de la Serna C, Sanz E, Martín de Argila $\mathrm{C}$, et al. Helicobacter pylori and bleeding duodenal ulcer: prevalence of the infection, efficacy of three triple therapies and role of eradication in the prevention of recurrent hemorrhage. Med Clin (Barc) 1999; 112: 161-5.

21. Calvet X, Ducons J, Bujanda L, Bory F, Montserrat A, Gisbert JP, for the HP Study Group ot the Asociación Española de Gastroenterología. Seven versus ten days of rabeprazole triple therapy for Helicobacter pylori eradication: a multicenter randomized trial. Am J Gastroenterol 2005; 100: 1696-701.

22. Boixeda D, Martín de Argila C, Bermejo F, López Sanroman A, Hernández Ranz F, Gracía Plaza A. Seven-day proton pump inhibitor, amoxicillin and clarithromycin triole therapy. Factors that influence Helicobacter pylori eradication success. Rev Esp Enferm Dig 2003; 95: 202-5.

23. Gisbert JP, De la Morena F. Systematic review and meta-analysis: levofloxacin-based rescue regimens after Helicobacter pylori treatment failure. Aliment Pharmacol Ther 2006; 23: 35-44.

24. Gisbert JP, Bermejo F, Castro-Fernández M, Pérez-Aisa A, Fernández-Bermejo M, Tomas A, et al. Second-line rescue therapy with levofloxacin after $\mathrm{H}$. pylori treatment failure: A Spanish multicenter study of 300 patients. Am J Gastroenterol 2008; 103: 71-6.

25. Gisbert JP, Castro-Fernández M, Bermejo F, Pérez-Aisa, Ducons J, Fernández-Bermejo M, et al. Third-line rescue therapy with levofloxacin after two H. pylori treatment failures. Am J Gastroenterol 2006; 101: 243-7.

26. Bogaerts P, Berthin C, Nizet H, Glupczynski Y. Prevalence and mechanisms of resistance to fluoroquinolones in Helicobacter pylori strains from patients living in Beligium. Helicobacter 2006; 11: 4415 .

27. Zullo A, Perna F, Hassan C, Ricci C, Saracino I, Morini S, et al. Primary antibiotic resistance in Helicobacter pylori strains isolated in northern and central Italy. Aliment Pharmacol Ther 2007; 25: 142933.

28. Pajares García JM, Pajares-Villarroya R, Gisbert JP. Helicobacter pylori infection: antibiotic resistance. Rev Esp Enferm Dig 2007; 99: 63-70.

29. Wu DC, Hsu PI, Wu JK, Opekun AR, Graham DY. Randomized controlled comparison of sequential and quadruple (concomitant) therapies for H. pylori infection. Gastroenterology 2008; 134 (Supl. I): 137

30. Sánchez-Delgado J, Calvet X, Bujanda L, Gisbert JP, Titó L, Castro M. Ten-day sequential treatment for Helicobacter pylori eradication in clinical practice. Am J Gastroenterol 2008; 103: 2220-3. 